Session 2560

\title{
The Participation of Students in the Transfer of Technology with Regard to Probabilistic Design Methodology.
}

\author{
Landon C. Onyebueke, Chinyere Onwubiko \\ Tennessee State University
}

\begin{abstract}
:
The variability and complexity of human needs and demands always lead to advancement in technology, new discoveries and hence, the need for technology transfer.

Probabilistic Design Methodology (PDM) is a computational simulation method based on simple engineering models. It is concerned with the probability of non-failure performance of structures or machine elements. This technology has been successfully applied to various loading conditions encountered during space flights. However, this technology is yet to be accepted in the industries. This paper uses PDM to demonstrate the role of students in the transfer of technology.

Included in the paper are overview of PDM, the different stages that are necessary in preparing students for effective technology transfer. Projects carried out by engineering students at Tennessee State University are used to illustrate the features of PDM and how students can be used as a means for the transfer of the technology to industries.
\end{abstract}

\section{Introduction:}

The effectiveness of any new technology is reflected in its usefulness. Its popularity depends on the application and success in transferring the technology.

One of the most important areas in engineering that requires precision and accuracy is engineering design. Engineering design mostly depended on deterministic design methodology. As a result, deterministic design has reached a very high level of sophistication to the point that modern computational techniques make it possible to determine the stresses, strain and displacement of complex structures. In deterministic design the contingency of failure is totally discounted, which leads to the choice of a high factor of safety.

Unfortunately, the design of structures are really clouded with uncertainties. The fact that deterministic design methodology does not account for uncertainties in a direct manner makes it impossible to know when a system is over-designed or vice versa. This fact has led to a more focus on PDM. PDM is increasing in popularity among researchers due to the fact that it takes into consideration reliability, optimization, cost parameters and the sensitivity of design parameters. Deterministic method, which is the most common design method in the design of machine elements lacks most of these features. Probabilistic design approach is concerned with the probability of non-failure performance of structures or machine elements. It is much more useful in situations where the design is characterized by complex geometry, possibility of catastrophic failure or sensitive loads and material properties. The PDM normally requires a lot of computation but the advancement in technology has reduced the rigors that normally accompany 
most of the analyses involved. This method is used at the moment in a limited way due to the following facts:

1. Most people are unaware of the capabilities of the PDM and the available computer codes.

2. There is very little information available on most design parameters.

However there is a growing evidence that the PDM is beginning to attract more attention. The evidences include the growing number of reliability-oriented specialty conferences, short courses, sponsored research, research papers, and technical books ${ }^{1-5}$. The PDM and the information it provides are becoming more widely understood and better appreciated.

This technology is not yet common in the industries. In order to transfer the technology effectively to the industries, students must participate in the program. The stages necessary for students participation in technology transfer can be outlined as follows:

1. Recruitment of students.

2. Teaching the students the new technology and equipping them with required tools.

3. Test their understanding of the technology by involving them in projects that will require the application of the technology.

4. Sending students to industries that may need the technology.

\section{Overview of PDM:}

Probabilistic design approach is concerned with the probability of failure or preferably, reliability, the probability that a structure will realize the function assigned to it without failure. In a probabilistic structural analysis, the primitive (random) variables that affect the structural behavior have to be identified. These variables, which include temperature, material properties, structural geometry and loading conditions, must be described by their respective probability distributions. The amount of information contained in the output data is equivalent to the amount of information required for the input data. Some of the probabilistic analysis methods that have been developed are described by Rajagopal et $a^{6}$. These methods are:

1. Approximate evaluation of the mean and variance of functions through Taylor series expansion

2. Monte Carlo simulation and variation

3. Limit State function approach

4. Hybrid approach in which the most probable point or directional information from limit state function approach is used to reduce the sample space in simulation methods.

The analysis method applied in this demonstration is the limit state approach. This method requires the designer to define the limit state functions applicable to a given design problem. The limit state function or $\mathrm{g}$-function is a function of a vector of basic random variables, $\mathrm{X}=\left(\mathrm{Xl}, \mathrm{X}_{2},---\mathrm{X}_{\mathrm{n}}\right)$, with $\mathrm{g}(\mathrm{X})=\mathrm{O}$ being the limit state surface that separates the design space into two regions, namely, the failure $(\mathrm{g} \leq \mathrm{O})$ and the safe $(\mathrm{g}>\mathrm{O})$ regions. Given the point probability density function $(\mathrm{PDF}), \mathrm{f}_{\mathrm{X}}(\mathrm{X})$, the probability of failure in the failure domain $\Omega$ is,

$$
p_{f}=\int_{\Omega}---\int f_{X}(X) d X
$$

This multiple integral is difficult to evaluate directly for complicated g-function. It can be computed using a straight forward standard Monte Carlo procedure which is usually time consuming. The limit state function method applies the Most Probable Point (MPP) search approach (see figure 1). Several approaches are available to search for the MPP. One efficient method in use is the Advanced Mean Value method 
(AMV). This method provides efficient cumulative distribution function (CDF) analysis as well as reliability analysis ${ }^{7}$. Another method that is considered efficient as well is the Adaptive Importance Sampling Method (AIS). This method focuses on minimizing the sampling domain in the search space after the MPP is identified. The AIS method is generally used for system reliability analysis ${ }^{8}$.

The analytical process involved in the limit state approach has been illustrated elsewhere ${ }^{9}$. For any given $g$-function, there exists one or more solutions that satisfy the condition of $g(\mathbf{X})=0$ with locally or globally maximum joint probability density. One of these solutions is the MPP in the X-space. In some computational codes (e.g. NESSUS ) the MPP is defined in a transformed space called the u-space (in which the $u^{\prime}$ 's are independent) to facilitate probability computations ${ }^{10}$. By transforming $g(\mathbf{X})$ to $g(\mathbf{u})$, the most probable point, $\mathrm{u}^{*}$ on the limit state, $\mathrm{g}(\mathbf{X})=0$, is the point which defines the minimum distance from the origin to the limit state surface. This value is referred to as the safety index, $\beta$. Figure 1 illustrates a MPP diagram.

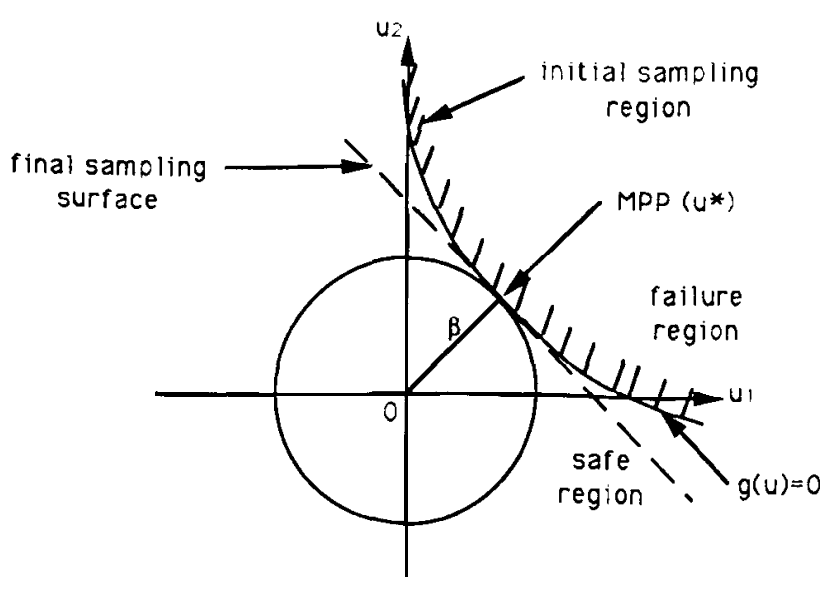

Figure 1:illustration of the Most Probable Point (MPP)

\section{Computational Tool:}

One of the software tools available for determining MPP and $p_{\mathrm{f}}$ is NESSUS. It has three different modules known as NESSUS/PRE, NESSUS/FEM and NESSUS/FPI. These modules are described by Shah et $\mathrm{al}^{11}$. Incorporated into the NESSUS/FPI module is a sensitivity analysis program. The sensitivity analysis factors computed by this module indicate which random variables are crucial and require special attention. The equation employed for the sensitivity analysis is the Multi-factor Interaction Equation (MFIE) given by Shah et $\mathrm{al}^{11}$. The general form of the equation is given by:

$$
\frac{M_{p}}{M_{p o}}=\prod_{i=1}^{N}\left[\frac{V_{f}-V}{V_{f}-V_{0}}\right]_{i}^{a}
$$

Where

$M_{p}$ represents degraded material property, $M_{p o}$ represents reference material property, $V$ denotes an effect and the subscripts $\mathrm{O}$ and $\mathrm{f}$ represent conditions at reference and final stages respectively. a and $\mathrm{i}$ are user defined.

In order to prepare the students adequately for the technology transfer, they are taught how to write a simple program that will compute the approximate value of the MPP. The program is based on the following analysis: 
Define a performance function for a system,

$$
g(x)=g(x, x,, \ldots, x n)
$$

where $\mathrm{X}=\left(\mathrm{X}_{1}, \mathrm{X}_{2}, . ., \mathrm{X}_{\mathrm{n}}\right)$ is a vector of basic state variables of the system. The limit state function is defined as

$$
\mathrm{g}(\mathrm{x})=\mathrm{o}
$$

In terms of reduced variates, $\mathrm{X}_{\mathrm{i}}^{\prime}$, the limit-state equation is

$$
\mathrm{g}\left(\sigma_{\mathrm{X} 1} \mathrm{X}_{1}^{\prime}+\mu_{\mathrm{X} 1}, \ldots, \sigma_{\mathrm{Xnn}}^{\mathrm{rn}^{\prime}}+\mu_{\mathrm{Xn}}\right)=0
$$

where

$$
X_{i}^{\prime}=\frac{X_{i}-\mu_{X_{i}}}{\sigma_{X_{i}}} ; \quad i=1,2, \ldots, n
$$

First order interpretation ${ }^{12}$ :

The performance function $\mathrm{g}(\mathrm{X})$ is expanded in a Taylor series at a point $\mathrm{x}^{*}$, which is on the failure surface $\mathrm{g}\left(\mathbf{x}^{*}\right)=\mathrm{O}$; that is,

$$
\begin{gathered}
g\left(X_{1}, X_{2}, \ldots, X_{n}\right)=g\left(x_{1}^{*}, x_{2}^{*}, \ldots, x_{n}^{*}\right)+\sum_{i=1}^{n}\left(X_{i}-x_{i}^{*}\right)\left(\frac{\partial g}{\partial X_{i}}\right)_{*} \\
+\sum_{j=1}^{n} \sum_{i=1}^{n}\left(X_{i}-x_{i}^{*}\right)\left(x_{j}-x_{j}^{*}\right) /\left(\frac{\partial^{2} g}{\partial X_{i} \partial X_{j}}\right)_{*}+\ldots
\end{gathered}
$$

where the derivatives are evaluated at $\left(\mathrm{x}_{1}^{*}, \mathrm{x}_{2}{ }^{*}, \ldots, \mathrm{x}_{\mathrm{n}}{ }^{*}\right)$. But $\mathrm{g}\left(\mathrm{x}_{1}{ }^{*}, \mathrm{X}_{2}{ }^{*}, \ldots, \mathrm{x}_{\mathrm{n}} *\right)=0$ on the surface; therefore

$$
\begin{aligned}
& g\left(X_{1}, X_{2}, \ldots, X_{n}\right)=\sum_{i=1}^{n}\left(X_{i}-x_{i}^{*}\right) \frac{\partial q}{\left.\partial X_{i}\right)_{*}} \\
& +\sum_{j=1}^{n} \sum_{i=1}^{n}\left(x_{i}-x_{i}^{*}\right)\left(x_{j}-x_{j}^{*}\right) /\left(\frac{\partial^{2} g}{\partial x_{i} \partial X_{j}}\right)_{*}+\ldots
\end{aligned}
$$

Note that,

$$
\begin{aligned}
\mathrm{xi}-\mathrm{x}_{\mathrm{i}}{ }^{*}=\left(\sigma_{\mathrm{Xi}} \mathrm{X}_{\mathrm{i}}{ }^{\prime}+\mu_{\mathrm{Xi}}\right)-\left(\sigma_{\mathrm{Xi}} \mathrm{X}_{\mathrm{i}}{ }^{*}+\mu_{\mathrm{Xi}}\right)=\sigma_{\mathrm{Xi}}\left(\mathrm{X}_{\mathrm{i}}{ }^{\prime}-\mathrm{X}_{\mathrm{i}}{ }^{*}\right) \\
\\
\text { A }
\end{aligned}
$$


and

$$
\frac{\partial g}{\partial X_{i}}=\frac{\partial g}{\partial X_{i}^{\prime}}\left(\frac{\partial X_{i}^{\prime}}{\partial X_{i}}\right)=\frac{1}{\sigma_{X_{1}}}\left(\frac{\partial g}{\partial X_{i}^{\prime}}\right)
$$

Then

$$
g\left(X_{1}, X_{2}, . ., X_{n}\right)=\sum_{i=1}^{n}\left(X_{i}^{\prime}-X_{i}^{\prime *}\right)\left(\frac{\partial g}{\partial X_{i}^{\prime}}\right)_{*}+\ldots
$$

In first-order approximation, that is, truncating the above series at the first-order term, the approximate value of the mean and the variance of the function $g(X)$ (for uncorrelated variate) are:

$$
\begin{gathered}
\mu_{g} \simeq-\sum_{i=1}^{n} X_{i}^{\prime *}\left(\frac{\partial g}{\partial X_{i}^{\prime}}\right)_{*} \quad(10) \\
\sigma_{g}^{2} \simeq \sum_{i=1}^{n} \sigma_{X_{i}^{\prime}}^{2}\left(\frac{\partial g}{\partial X_{i}^{\prime}}\right)_{*}=\sum_{i=1}^{n}\left(\frac{\partial g}{\partial X_{i}^{\prime}}\right)_{*}^{2}
\end{gathered}
$$

From equations (1 O) and (11) we obtain,

$$
\frac{\mu_{g}}{\sigma_{g}}=\frac{-\sum_{i=1}^{n} x_{i}^{\prime *}\left(\frac{\partial g}{\partial X_{i}^{\prime}}\right)_{*}}{\sqrt{\sum_{i=1}^{n}\left(\frac{\partial g}{\partial X_{i}^{\prime}}\right)_{*}^{2}}}
$$

The most probable failure point of this equation is

$$
x_{i}^{\prime *}=-\alpha_{i}^{*} \beta
$$

in which $\alpha_{i}$ are the direction cosines and is given by 


$$
\boldsymbol{\alpha}_{i}^{*}=\frac{\left(\frac{\partial g}{\partial X_{i}^{\prime}}\right)_{*}}{\sqrt{\sum_{i}\left(\frac{\partial g}{\partial X_{i}^{\prime}}\right)_{*}^{2}}}
$$

The above analysis is summarized in the following simple numerical algorithm by Rackwitz 2 .

1. Assume initial values of $\mathrm{xi}^{*} ; \mathrm{i}=1,2, \ldots \mathrm{n}$ and obtain

$$
x_{i}^{\prime *}=\frac{x_{i}^{*}-\mu_{x_{i}}}{\sigma_{x_{i}}}
$$

2. Evaluate $\left(\partial g / \partial X_{i}^{\prime}\right)$ and $\alpha_{i}^{*}$ at $x$

3. From $X i '=\mu_{x i}-\alpha_{i}{ }^{*} \sigma_{x i} \beta$

4. Substitute above $\mathrm{xi}^{*}$ in $\mathrm{g}\left(\mathrm{x}_{1} *, \mathrm{x}_{2}{ }^{*}, \ldots, \mathrm{x}_{\mathrm{n}}{ }^{*}\right)=\mathrm{O}$ and solve for $\beta$

5. Using $\beta$ obtained in step 4 , reevaluate $\mathrm{xi}^{*} *=-\alpha_{\mathrm{i}}^{*} \beta$

6. Repeat steps 2 through 5 until convergence is obtained.

The above analysis can be adjusted for non-normal distributions and correlated variables.

\section{Students' Involvement:}

Students were given projects that will require the application of NESSUS. They were also given assignments that required them to write a computer program based on the above numerical algorithm and to compare the results obtained with that of NESSUS. Tables 1 and 2 are the design input data for design examples 1 and 2. Figures 2 to 5 show the results obtained by students for defined performance functions. The results reflect some of the features of the PDM. Table 4 represents a comparison of the results obtained using NESSUS and the program written by students.

Design example 1. Design of a helical spring considering two failure modes where the limit state functions are defined as follows ${ }^{13}$ :

$$
g_{\tau}=S-\frac{(8 *}{\left.D_{m} * F_{0} * k\right)_{-}}
$$




$$
g_{\Delta}=\left(L_{f} * 2.48 e^{-0.315\left(\frac{L_{f}}{D_{m}}\right)}\right)-\frac{8 * F_{o} * D_{m}^{3} * N_{a}}{G * D_{\mathrm{w}}^{4}}
$$

Table 1 isthedesign input data for equations (15) and (16).

Table 1: Input data

\begin{tabular}{||l|l|l|l||}
\hline \hline Variable & Mean & Standard deviation & Distribution type \\
\hline $\mathrm{S}(\mathrm{psi})$ & $1.30 \mathrm{E}+4$ & $3.25 \mathrm{E}+2$ & normal \\
\hline $\mathrm{F}_{\mathrm{o}}(\mathrm{lbs})$ & 20 & 5 & normal \\
\hline $\mathrm{D}_{\mathrm{m}}(\mathrm{in})$ & $7.50 \mathrm{E}-1$ & $7.50 \mathrm{E}-2$ & normal \\
\hline $\mathrm{D}_{\mathrm{w}}(\mathrm{in})$ & $2.30 \mathrm{E}-1$ & $2.30 \mathrm{E}-2$ & normal \\
\hline $\mathrm{L}_{\mathrm{f}}(\mathrm{in})$ & 6 & 1 & normal \\
\hline $\mathrm{G}(\mathrm{psi})$ & $1.12 \mathrm{E}+7$ & $6.40 \mathrm{E}+4$ & normal \\
\hline $\mathrm{N}_{\mathrm{a}}$ & 5 & 1 & normal \\
\hline \hline
\end{tabular}

where,

$\mathrm{g}_{\tau}=$ limit state function for torsional shear stress failure mode

$\mathrm{S}=$ design limit ultimate strength of the spring material

(Chromium-Vanadium)

$\mathrm{D}_{\mathrm{m}}=$ mean diameter

$\mathrm{F}_{\mathrm{o}}=$ Force on spring

$\mathrm{k}=$ Wahl constant

$\mathrm{D}_{\mathrm{w}}=$ wire diameter

$\mathrm{g}_{\Delta}=$ limit state function for deflection failure mode

$\mathrm{L}_{\mathrm{f}}=$ free length

$\mathrm{N}_{\mathrm{a}}=$ Number of active coils

$\mathrm{G}=$ spring modulus of elasticity

The student studied the relationship between the probability of failure and the weight of the spring. This is presented in figure 2. Figure 3 is the curve of the probability of failure as a function of the coefficient of variance of the wire diameter. In figure 2 it is observed that the probability of failure decreases with increase in the weight of spring. It also illustrates that after a certain amount of increase of the weight, any further increase becomes ineffective. Figure 3 shows that the probability of failure increases with increase of the coefficient of variance of the wire diameter. In other words, the probability of failure increases as the uncertainty increases. 
$\mathrm{V}_{\mathrm{g}}=$ Poisson's ratio of the gear material

$\mathrm{MC}=$ contact ratio

$\mathrm{L}_{\mathrm{a}}=$ length of the line of action

Table 2 is the design input data for equations (17) and (18).

Table 2: Input data

\begin{tabular}{||l|l|l|l||}
\hline \hline Variables & Mean & Standard deviation & Distribution type \\
\hline $\mathrm{S}_{\mathrm{L}}(\mathrm{psi})$ & $30 \mathrm{E}+3$ & $1.0 \mathrm{E}+3$ & normal \\
\hline $\mathrm{W}_{\mathrm{t}}(\mathrm{lb})$ & 650 & 20 & normal \\
\hline $\mathrm{F}_{\mathrm{w}}(\mathrm{in})$ & 1.5 & 0.07 & lognormal \\
\hline $\mathrm{Y}_{\mathrm{f}}$ & 0.409 & 0.02 & lognormal \\
\hline $\mathrm{P}_{\mathrm{d}}($ teeth/in) & 8 & 1 & normal \\
\hline $\mathrm{E}_{\mathrm{p}}(\mathrm{psi})$ & $30 \mathrm{E}+6$ & $1.5 \mathrm{E}+6$ & normal \\
\hline $\mathrm{E}_{\mathrm{g}}(\mathrm{psi})$ & $14.5 \mathrm{E}+6$ & $7.25 \mathrm{E}+5$ & normal \\
\hline $\mathrm{R}_{1}(\mathrm{in})$ & 0.342 & 0.081 & lognormal \\
\hline $\mathrm{R},(\mathrm{in})$ & 1.069 & 0.20 & lognormal \\
\hline $\mathrm{L}_{\mathrm{a}}(\mathrm{in})$ & 0.736 & 0.11 & lognormal \\
\hline $\mathrm{MC}$ & 2.5 & 0.1 & normal \\
\hline $\mathrm{P}(\mathrm{in})$ & 0.392 & 0.1 & lognormal \\
\hline $\mathrm{S}_{\mathrm{c}}(\mathrm{psi})$ & $55 \mathrm{E}+3$ & $2.0 \mathrm{E}+3$ & normal \\
\hline $\mathrm{V}_{n}$ & 0.292 & 0 & \\
\hline $\mathrm{V}_{\mathrm{g}}$ & 0.211 & 0 & \\
\hline \hline
\end{tabular}

The student presented the sensitivity analysis and the probability of failure for each of the limit state functions as illustrated in figures (4) and (5).

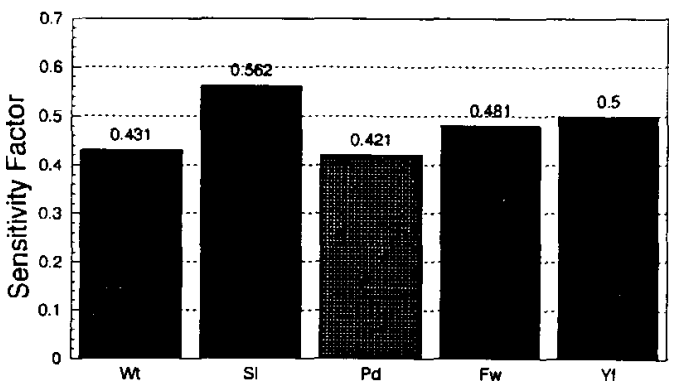

Figure 4: Sensitivity factors for the design parameters in gl (Probability of failure, $\mathrm{Pf}=\mathbf{0 . 0 4 5 5 )}$

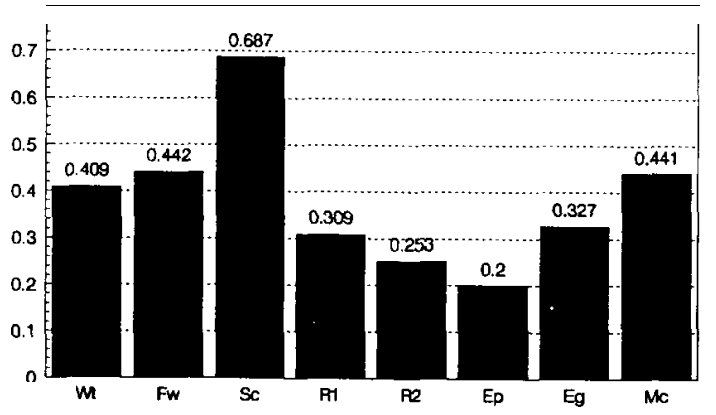

Figure 5: Sensitivity factors for the design parameters in g2 (Probability of failure,

$$
P f=0.0672)
$$


A probability fault tree analysis method ${ }^{15}$ was applied in the computation of the probability of failure of the system. The system probability of failure, $\mathrm{P}_{\mathrm{f}}$, was found to be 0.0701 .

Design example 3. Design of a cantilever beam considering only one failure mode where the limit state function is defined as:

$$
g_{D}=\Delta_{L}-\frac{4 * Q * I^{3}}{E * b * h^{3}}
$$

Table 3 is the design input data for equation (19).

Table 3: Input data

\begin{tabular}{||l|l|l|l||}
\hline \hline Variable & Mean & Standard deviation & Distribution type \\
\hline$\Delta_{\mathrm{L}}$ (in) & 0.75 & 0.042 & normal \\
\hline Q (kips) & 1.888 & 0.282 & normal \\
\hline L (in) & 18 & 0.9 & lognormal \\
\hline E (ksi) & $30 \mathrm{E}+3$ & 0 & \\
\hline b (in) & 1 & 0.05 & lognormal \\
\hline h (in) & 1.5 & 0 & \\
\hline \hline
\end{tabular}

where,

$$
\begin{aligned}
\Delta_{\mathrm{L}} & =\text { deflection limit of beam } \\
\mathrm{Q} & =\text { concentrated load on beam } \\
\mathrm{L} & =\text { length of beam } \\
\mathrm{E} & =\text { Young's modulus } \\
\mathrm{b} & =\text { with of beam } \\
\mathrm{h} & =\text { height of beam }
\end{aligned}
$$

Example 3 is analyzed using NESSUS and an equivalent program written by students. The results are summarized in table 4.

Table 4: Table of Comparison

\begin{tabular}{||l|l|l||}
\hline \hline Method & Safety index & Prob. of Failure \\
\hline Students' program & 2.53936 & $0.56880 \mathrm{E}-2$ \\
\hline || NESSUS & 2.53557 & $0.56132 \mathrm{E}-2$ \\
\hline \hline
\end{tabular}




\section{Strategy:}

The aim of this exercise is to involve the students in the program in such a way that they will have a full knowledge of the technology. The fact that the students can write their own programs means that they can demonstrate the technology in any industry even when the industry has no standard PDM software. It gives the students the opportunity to use any available computer hardware. It also makes it possible for industries to have a good idea of the features of the technology without much financial commitment.

\section{Conclusion:}

The steps necessary for preparing students to participate in the transfer of technology has been illustrated. The effectiveness of this participation depends on how well the students are trained in the new technology. In the case of PDM, the fact that the students are trained to write their own program reduces their limitations when they go to industries that do not have any standard PDM software. Most industries will be more willing to try a new technology that requires little or no capital commitment than when a huge capital is involved.

\section{Acknowledgement:}

This material is based upon work supported by NASA (Lewis Research Center) under grant NAG3-1479 and it is gratefully acknowledged.

\section{References:}

1. Cruse T.A. et al. "An Overview of the NASA (LeRc)-SwRI Probabilistic Structural Analysis (PSAM) Program”. Structural safety \& reliability proceedings of ICOSSAR “89/ 5th Int '1. Conf. San Francisco, pp 2267-2274.

2. Southwest Research Institute, "4th Annual Short Course on Computational Methods for Probabilistic Analysis". SWRI, San Antonio, Texas; September 13-17, 1993.

3. Cruse T.A. et al. "Probabilistic Structural Analysis Methodology and Applications to Advanced Space Propulsion System Components". Computing Systems in Engineering, vol. 1, nos 2-4, pp 365-372, 1990.

4. Thomson D.E. and Feck T. G., “Air Force Perspective on Probabilistic Design”. AD-vol. 28, Reliability Technology ASME 1992, pp 25-32

5. Melchers R.E; Structural Reliability, Analysis and Prediction. Publisher: Ellis Horwood Limited.

6. Rajagopal K.R. et al. "Reliability of Advanced Space Propulsion components". AD-vol. 28, Reliability Technology, ASME, 1992, pp 189-198.

7. Wu Y.-T et al. "Advanced Probabilistic Structural Analysis Method for Implicit Performance Function". AIAA Journal, vol. 28, no. 9, September 1990, pp 1663-1669.

8. Wu Y.-T. "An Adaptive Importance Sampling Method For Structural System Reliability Analysis". $A D-$ vol. 28, Reliability Technology, ASME 1992, pp 217-231. 
9. Onyebueke L.C. and Onwubiko C. Probabilistic Design Methodology and Application to Machine Element Design”. Presentation at the third Int'l conf. on stochastic structural dynamics, San Juan, Puerto Rico, Jan. 15-18.1995.

10. Southwest Research Institute. "NESSUS/FPI Theoretical Manual, NASA Contract NAS3-24389". December 1989.

11. Shah A.R. et al, "Probabilistic Evaluation of Uncertainties and Risks in Aerospace Components". NASA Technical Memorandum 105603, March 1992.

12. Ang A. H-S and Tang W.H. Probability Concepts in Engineering Panning and Design; vol. 2 decision, risk, and reliability; Published by the authors, 1990.

13. Higgs III, C.F. "Using Probabilistic Design Methodology in the Design of a Helical Spring". Senior year design project, 1995, Department of Mechanical Engineering, Tennessee State University.

14. Ogbonna D.C. "Design of a High Performance Spur Gear Using Probabilistic Design Methodology". Senior year design project, May 1995, Department of Mechanical Engineering, Tennessee State University.

15. Torng T. et al., "Structural System Reliability Calculation Using a Probabilistic Fault Tree Analysis Method". 33rd AIAA/ASME/AHS/ASC Structures, Structural Dynamics and Materials Conference, April 1992, pp.603-613.

LANDON C. ONYEBUEKE is a Research Associate in the Department of Mechanical Engineering at Tennessee State University. He holds a Ph.D and M.S in Mechanical Engineering from Institut National Polytechnique de Lorraine, Nancy, France and B.S in Mechanical Engineering from University of Ibadan, Nigeria. He has done a lot of work and published papers in the area of heat transfer in porous media. He is currently working on Probabilistic and Axiomatic Design Methodologies, a project being funded by NASA.

CHINYERE ONWUBIKO is a Professor and Head of Mechanical Engineering at Tennessee State University. He holds Ph.D and B.S in Mechanical Engineering from Mississippi State University and M.S from Southern Methodist University, Dallas, Texas. He is a Registered Professional Engineer. He has several publications in the area of Engineering Design Optimization, Design for Manufacturability and Probabilistic Design Methodology. 